\title{
PRIMÓRDIOS DA CRÔNICA DE AUTORIA FEMININA NO BRASIL E A LUTA PELA IGUALDADE DE GÊNERO
}

\author{
PEREIRA, Maria do Rosário Alves ${ }^{1}$
}

\begin{abstract}
RESUMO: O objetivo deste artigo é traçar breves apontamentos críticos sobre a história da crônica de autoria feminina publicada no Brasil desde seu surgimento no século XIX até o começo do século XX. Esse gênero híbrido, que toma forma a partir do folhetim francês, tem importante papel na divulgação dos ideais feministas e na luta pela igualdade entre os sexos por meio da educação. A partir de Constância Lima Duarte e Dulcília Buitoni, dentre outros autores, procura-se demonstrar como a crônica escrita por mulheres, juntamente com a imprensa feminista, teve importante papel na defesa por direitos das mulheres tanto no campo educacional quanto no político.
\end{abstract}

PALAVRAS-CHAVE: crônica, autoria feminina, imprensa feminista, Brasil, século XIX.

\section{COMIENZOS DE LA CRÓNICA DE AUTÓRIA FEMENINA EN BRASIL Y LA LUCHA POR IGUALDAD DE GÉNERO}

RESUMEN: El propósito de este artículo es extraer breves notas críticas sobre la historia de la crónica de autoría femenina publicada en Brasil desde su aparición en el siglo XIX hasta principios del siglo XX. Este género híbrido, que se constituye a partir del folleto francés, tiene un papel importante en la difusión de los ideales feministas y en la lucha por la igualdad de género a través de la educación. Desde Constância Lima Duarte y Dulcília Buitoni, entre otros autores, buscamos demostrar cómo la crónica escrita por mujeres, junto con la prensa feminista, tuvo un papel importante en la defensa de los derechos de las mujeres tanto en el campo educativo como político.

PALABRAS CLAVE: crónica, autoría femenina, prensa feminista, Brasil, siglo XIX.

\footnotetext{
${ }^{1}$ Professora de Língua Portuguesa, Literatura Brasileira e Edição do CEFET-MG. Doutora em Estudos Literários - Literatura Brasileira pela UFMG. Endereço eletrônico: mariadorosario58@gmail.com 


\section{Elucubrações em torno do gênero crônica}

Gênero híbrido, que perpassa os territórios da literatura e do jornalismo, a crônica tem servido, muitas vezes, como registro histórico de seu tempo. Porém, se é fato que se trata de um texto que traz informação, que noticia e reflete sobre os acontecimentos mais insignificantes do dia a dia, por outro lado ultrapassa em muito tal dimensão, elevando tais acontecimentos à categoria de maior importância. Nas palavras de Antonio Candido (1992, p. 13), em célebre artigo sobre o gênero: "Por meio dos assuntos, da composição aparentemente solta, do ar de coisa sem necessidade que costuma assumir, ela se ajusta à sensibilidade de todo o dia." A referência ao tempo já está presente na própria etimologia da palavra, que vem do grego "Cronos", numa alusão à divindade que seria a personificação do tempo. Neste artigo, interessa-nos traçar algumas reflexões em torno do surgimento da crônica brasileira de autoria feminina no século XIX, mostrando o quanto este gênero serviu como registro histórico da luta feminista pela educação e modernização da mulher. Primeiramente, faz-se relevante retomar algumas considerações de Constância Lima Duarte no artigo "Feminismo e literatura no Brasil" (2003).

De acordo com a autora, quatro teriam sido as "ondas" principais do movimento feminista brasileiro, a saber: i) 1830: poucas mulheres abastadas começam a acessar a leitura e a escrita; ii) 1870: essas poucas mulheres letradas começam a publicar em jornais e a produzir jornais inteiramente dedicados à causa feminista; iii) 1920: a luta pelo voto feminino ganha corpo; iv) 1970: na "década da mulher", dá-se a chamada "revolução sexual", em que predomina a luta pela emancipação feminina a partir de demandas ligadas ao corpo, como o direito de escolha à maternidade, direito este potencializado pela chegada da pílula anticoncepcional. É no século XIX, então, que a mulher brasileira começa, ainda que paulatinamente, a acessar a escrita e a leitura, e é por meio desses dois instrumentos de poder que o status quo começa a se modificar.

No que se refere à crônica especificamente, esta nasce com o jornal, a partir do folhetim, conforme esclarece Marlyse Meyer em "Voláteis e versáteis, de variedades e folhetins se fez a chronica": "De início - começos do século XIX - le feiulleton designa um lugar preciso do jornal: o rez-de-chaussée - rés-do-chão, rodapé, geralmente da primeira página. Tem uma finalidade precisa: é um espaço vazio destinado ao entretenimento.” (MEYER, 1985, p. 19) Esse espaço do "vale-tudo" trazia questões do cotidiano relacionadas à política, à arte, à literatura e à sociedade em geral, incluindo relatos de viagem, descrições de usos e costumes, 


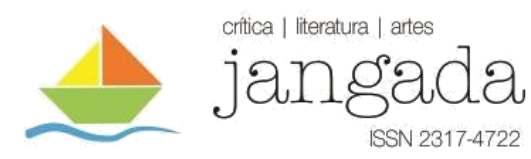

charadas, receitas de cozinha ou de beleza, resenhas de peças e de livros e até histórias de cunho moralista. Tudo aquilo que não se enquadrava nas demais seções do jornal encontrava refúgio seguro no folhetim. Muitos romances, inclusive, foram inicialmente publicados neste espaço, o que exigia do escritor habilidade para finalizar seu texto deixando um "gancho", um tom de expectativa ou mesmo mistério para que o leitor se interessasse em continuar acompanhando aquele enredo. Ainda segundo Meyer, por volta dos anos de 1836, "a fórmula continua amanhä" havia se tornado corriqueira e angariava cada vez mais leitores, os quais se viam "obrigados" a adquirirem novo jornal a cada semana.

\section{A crônica em terras brasileiras e a imprensa feminista}

O folhetim aparece em solo brasileiro por influência da imprensa francesa, com características semelhantes ao feuilleton, que era publicado uma vez por semana, preferencialmente aos domingos, no rodapé da primeira página. No Brasil, no entanto, nem sempre era publicado com essa regularidade, e por vezes tal espaço dava conta de até 15 dias de acontecimentos. Talvez seja por isso que Machado de Assis tenha afirmado, em texto publicado no Correio Mercantil de 30 de outubro de 1859, que "uma das plantas europeias que dificilmente se têm aclimatado entre nós é o folhetinista”. E, mais adiante, assevera:

O folhetinista é a fusão admirável do útil e do fútil, o parto curioso e singular do sério, consorciado com o frívolo. Estes dois elementos, arredados como polos, heterogêneos como água e fogo, casam-se perfeitamente na organização do novo animal.

(...)

Força é dizê-lo: a cor nacional, em raríssimas exceções, tem tomado o folhetinista entre nós. Escrever folhetim e ficar brasileiro é na verdade difícil. (MACHADO DE ASSIS, 1859)

Sendo, portanto, um gênero importado, o folhetim, na visão machadiana, carecia de originalidade em terras brasileiras, e deveria "bem tomar mais cor local, mais feição americana". Seja como for, é fato que, com as transformações sofridas com o tempo, a crônica "aclimatou-se" admiravelmente em solo brasileiro, tratando dos mais diversos assuntos, desde fatos comuns à vida de todos, até questões mais específicas, como as que concernem ao universo feminino, como se verá.

Todo esse movimento só foi possível, entretanto, com o advento da imprensa no Brasil, em 1816. A chegada da família real, em 1808, e a instalação da corte portuguesa no Rio de 


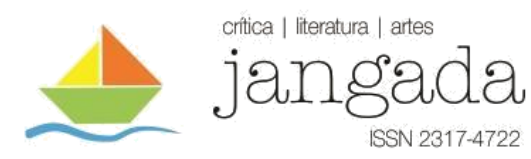

Janeiro transformaram essa localidade em ponto privilegiado para uma efervescência cultural e para que novos modos e hábitos europeus pudessem ser incorporados pela população brasileira. Intensifica-se o processo de urbanização e os textos publicados dão conta dessas mudanças, ao mesmo tempo que o próprio gênero crônica se alterava. Salienta-se que entre o início do século XIX e o início do XX as crônicas passavam por lentas modificações, acompanhando ao mesmo tempo as próprias transformações históricas que ocorriam.

Alguns eventos comprovam isso: a chegada da República traz novos ares à antiga colônia, e as mulheres, acostumadas a se enclausurar dentro de casa e de só sair às ruas trajando mantilhas pesadas e escuras que as cobriam literalmente dos pés à cabeça, começam a modificar seu modo de vestir, a ir à ópera, ao teatro. Inicia-se aí a construção de uma nova mulher brasileira, ocupada agora com a vida que a circundava, ao invés de ficar estritamente reclusa ao seio familiar. Segundo Gilberto Freyre, com a chegada da corte e a abertura dos portos, o Rio de Janeiro passou por um processo de "desassombramento": tudo que estava na sombra deveria vir à luz. ${ }^{2}$ Vale ressaltar que até 1814 as mulheres brasileiras estiveram fora da escola e poucas recebiam uma educação básica em casa, fato que impressionava negativamente os estrangeiros que aqui aportavam. Isabel Lustosa aponta:

Entre os costumes gradativamente modificados esteve a adoção de uma atitude mais moderna com relação ao lugar da mulher na sociedade. Essa mudança implicaria a necessidade de um certo nível de ilustração que possibilitasse à mulher fazer boa figura nos salões, teatros e reuniões que então passaram a ser parte da vida social do Rio de Janeiro. Mas essa mudança no plano da sociabilidade (...) teve suas raízes mais profundas na tendência de separação entre os espaços público e privado que vinha do século XVIII. Separação da qual resultara uma releitura da vida familiar e do papel da mulher naquele contexto. Com a independência e a emergência de um espírito constitucionalista nas maiores cidades brasileiras, a mulher passa a ser também um sujeito político importante, pois, como mãe, é a primeira instância de formação dos futuros brasileiros. (LUSTOSA, 2010, p. 13)

Dessa forma, começa a haver um redimensionamento no papel da mulher na sociedade: se ela era responsável pela formação de muitos jovens brasileiros, seria no mínimo razoável que tivesse educação e cultura para ser repassada - e não apenas um comportamento adequado

\footnotetext{
${ }^{2}$ Cf. ALMANAQUE MULHERES REAIS - MODAS E MODOS NO RIO DE DOM JOÃO VI. Exposição no Palácio das Artes, de 9/10 a 22/11/09, em Belo Horizonte, p. 17.
}

Jangada | nr. 15, jan/jun, 2020 | ISSN 2317-4722 


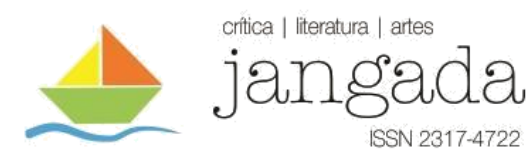

nas "aparências" -, o que lhe proporcionava maior traquejo social. Associações voltadas para o projeto de emancipação feminina começam a ser criadas, tais como o Partido Feminino Republicano; surge a acalorada discussão sobre o direito de votar ou não das mulheres; se dá a abertura do Colégio Pedro II, tradicional instituição de ensino público no Rio de Janeiro que, durante 90 anos, não permitiu o ingresso de estudantes do sexo feminino; e, por fim, o ensino superior acaba abrindo suas portas ao público feminino.

Foi um tempo em que surgiram pioneiras em várias áreas do conhecimento. No que diz respeito às escritoras não foi diferente. Constância Lima Duarte, em "Literatura, imprensa e emancipação da mulher no Brasil no século XIX”, esclarece que a literatura de autoria feminina, a consciência feminista e a imprensa de mulheres surgiram praticamente ao mesmo tempo no Brasil, pois assim que as primeiras mulheres tiveram acesso ao letramento, logo em seguida se apoderaram da leitura que, por sua vez, as conduziu à escrita e à crítica (DUARTE, 2010, p. 2). E os jornais foram o espaço privilegiado para que essa produção letrada feminina viesse à tona, num trabalho de certa forma pedagógico que visava à conscientização da sociedade sobre o papel da mulher e a necessidade de transformação de sua condição, para que ela ocupasse os espaços públicos, participando ativamente. De acordo com Zahidé Muzart:

Uma das razões para a criação dos periódicos de mulheres no século XIX partiu da necessidade de conquistarem direitos. Em primeiro lugar, o direito à educação; em segundo, o direito à profissão e, bem mais tarde, o direito ao voto. Quando falamos dos periódicos do século XIX, há que se destacar, pois, essas grandes linhas de luta. (MUZART, 2003)

Como se nota, a chamada "imprensa feminista" cumpriu papel fundamental no que se refere à luta pelos direitos das mulheres. É notório também o fato de que muitas escritoras utilizavam pseudônimos ou escreviam para pequenos jornais do interior, com público restrito e específico. O surgimento de periódicos dedicados ao sexo feminino e, posteriormente, produzidos por mulheres criam condições para o aparecimento dessas escritoras. O primeiro periódico brasileiro dedicado às mulheres, O Espelho Diamantino - Periódico de Política, Literatura, Belas Artes, Teatro e Modas, dedicado às Senhoras Brasileiras, surge em 1827, no Rio de Janeiro, e foi fundado por Pierre Plancher, responsável pelo Jornal do Comércio. Com periodicidade quinzenal, em 14 números publicou desde notícias sobre acontecimentos políticos até poemas e contos, passando por artigos de culinária e moda. Em seu primeiro número, o editorial já salientava o quão premente se fazia a instrução feminina: 


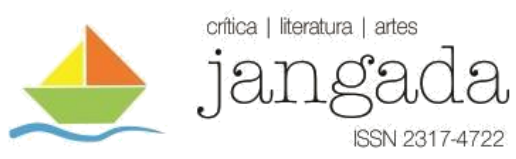

Tendo as mulheres uma parte tão principal nos nossos interesses e negócios, necessário é que se lhes dê conta destes mesmos negócios, e dos princípios que originam os deveres e os acontecimentos, para que elas fiquem à altura da civilização e dos seus progressos, pois que pretender conservá-las em um estado de preocupação, e estupidez, pouco acima dos animais domésticos, é uma empresa tão injusta como prejudicial ao bem da humanidade (...) $(O$ Espelho Diamantino, 1827, p. 3-4 apud DUARTE, 2016, p. 40)

Para que as mulheres pudessem, então, tomar parte nos negócios masculinos, auxiliando o desenvolvimento da própria sociedade como um todo, fazendo-a progredir seja em que meio atuassem, necessário era que se instruíssem, e não que fossem consideradas seres inferiores. Outros periódicos mantinham essa mesma verve de luta educacional: de 1829 a 1832, circulou em São João del-Rei, Minas Gerais, O Mentor das Brasileiras. Idealizado por José Alcebíades Carneiro, professor de Latim, tratava de assuntos diversos, e em seu primeiro editorial também era notório o propósito educacional para o sexo feminino: “As Senhoras, pelos deveres que lhes são inerentes, fazem o fundamento principal da sociedade humana, e por isso são dignas de uma instrução mais sólida, e capaz de promover o bem geral de uma Nação.” (O Mentor das Brasileiras, 1829, p. 2-4, apud DUARTE, 2016, p. 45) Surgem outros periódicos, preocupados com questões do universo feminino e redigidos pelas próprias mulheres, como se verá adiante.

\section{Primeiras cronistas: a educação e o sufrágio femininos em xeque}

Dulcília Buitoni, em "Crônica/mulher, mulher/crônica”, faz uma associação interessante entre os temas "crônica" e "mulher":

Crônica e mulher: uma relação raramente apontada, mas que apresenta muitos e antigos laços. Quando se pensa em crônica, a associação é: cronista homem. Aliás, os grandes cronistas brasileiros são homens. No entanto, houve e há cronistas mulheres. Mais ainda: mesmo de autores homens, os primeiros produtos em gênero incipiente que poderia ser chamado de crônica apareciam muito na imprensa feminina brasileira, isto é, eram dirigidos preferencialmente a um público de mulheres. (BUITONI, 1985, p. 81)

Ao destacar a imprensa feminina, a autora dá uma importante pista sobre o surgimento do gênero crônica também entre as mulheres, ao mesmo tempo que chama a atenção para o fato de que as primeiras escritoras brasileiras publicaram originalmente em jornais. Além disso, 
Buitoni postula como temas caros ao universo feminino "a mudança do tempo, o coloquial, a cidade, as modas" (p. 81), temas matrizes também da crônica, o que ratifica a associação entre mulher e crônica. Houve, assim, um período em que a crônica predominante era aquela vinculada a acontecimentos sociais e artísticos, mas em algumas escritoras o viés crítico predominava mesmo em meio a este cenário. Como exemplo podemos citar Júlia Lopes de Almeida (1862-1934), que em seus escritos discutiu temas variados, como a participação mais ativa da mulher na sociedade, sua educação, divórcio etc., e também abordou questões relacionadas ao abolicionismo e à república, tendo colaborado em periódicos como Gazeta de Notícias, Jornal do Comércio e A Semana. Em alguns de seus textos, vale-se da ironia para fazer denúncia, como em “Ah! os senhores feministas!”. Um eu masculino assume a voz narrativa do texto, e queixa-se das ausências da mulher, num "primeiro movimento de independência" bastante estranho a uma pessoa pouco afeita a saídas de casa e também à leitura, pois “Terezinha não lê, nem por acaso!” (ALMEIDA, 1922, p. 74) E completa:

Geralmente, minha mulher queixa-se de que eu converso pouco; pois aí está: hoje vinha com tenção de conversar... de falar detidamente sobre aquela proposta do Teles... não para the pedir conselhos, as opiniões dela não me esclarecem nada, mas só porque, enfim, quando raciocino em voz alta, penetro melhor no sentido das coisas... As mulheres fazem às vezes umas objeções imprevistas, extravagantemente ingênuas, mas que não raro sugerem certos pensamentos aproveitáveis... Não é que eu associe Terezinha às minhas empresas de importância; coitadinha, que competência tem ela para isso? mas porque, expondo-lhe o caso, tenho de reduzi-lo à máxima simplicidade para a sua compreensão... (ALMEIDA, 1922, p. 76)

Conforme se vê na passagem, a voz masculina deixa entrever um sistema patriarcal que permeia as relações sociais e, neste caso, matrimoniais de dominação do elemento masculino sobre o feminino. No caso, o jugo cultural/intelectual aparece fortemente, pois as opiniões da mulher "não esclarecem nada", e o assunto tem de ser deslindado com a "máxima simplicidade para a sua compreensão". No entanto, a ironia da autora se apresenta sutilmente, pois as “objeções ingênuas" do sexo feminino, paradoxalmente, "não raro sugerem certos pensamentos aproveitáveis". Ou seja: mais do que um bibelô sem forma, a mulher exerceria, ao contrário, influência sobre as decisões masculinas. Em outras crônicas e em seus textos puramente ficcionais, Júlia Lopes de Almeida lançou sementes para que o processo de mudança de 


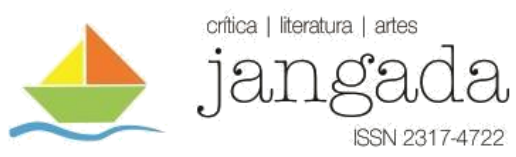

mentalidades no que diz respeito à condição feminina fosse acontecendo mesmo que paulatinamente. ${ }^{3}$

Periódicos em que a educação e a emancipação da mulher eram a tônica foram cada vez mais ganhando a cena: em 1852, Joana Paulo Manso de Noronha inaugura o Jornal das Senhoras, conhecido como o fundador do periodismo feminino, cujo objetivo era "propagar a ilustração, e cooperar com todas as suas forças para o melhoramento social e para a emancipação moral da mulher" (VASCONCELLOS, 1998, p. 11). Publicado no Rio de Janeiro, com circulação sempre aos domingos, a ousadia do periódico é visível já em seu primeiro número, em texto endereçado às assinantes:

Ora, pois, uma senhora a testa de uma redação de um jornal!

Que bicho de sete cabeças será?

Contudo em França, em Inglaterra, na Itália, na Espanha, nos Estados Unidos, em Portugal mesmo, os exemplos abundam de senhoras dedicadas à literatura colaborando [em] diferentes jornais. Porventura a América do Sul, ela só, ficará estacionária nas suas ideias, quando o mundo inteiro marcha ao progresso e tende ao aperfeiçoamento moral e material da Sociedade? $(O$ Jornal das Senhoras, 1852, p. 1, apud DUARTE, 2016, p. 118)

Joana Paula Manso chama a atenção para o fato de que, sobretudo na Europa, mulheres escreverem em jornais e inclusive encabeçá-los já era bem mais comum e aceito, e mais ainda, a educação feminina dava mostras do progresso de uma nação. Outro periódico relevante foi aquele editado por Senhorinha da Motta Diniz, O Sexo Feminino, o qual circulou de 1873 a 1876, primeiramente em Campanha da Princesa da Beira, Minas Gerais. Quando o jornal comemorou seu primeiro ano, sua fundadora mudou-se com as filhas para o Rio de Janeiro, na expectativa de que na corte a publicação tivesse maior alcance. Assim Francisca Senhorinha se dirigia, neste número, a seus leitores:

Devo prevenir ao sexo masculino que não pense que as mulheres estão adormecidas pelo sono do indiferentismo; não, algumas já se têm feito ouvir,

\footnotetext{
${ }^{3}$ Conforme destaca Nadilza Martins de Barros Moreira, em A condição feminina revisitada: Júlia Lopes de Almeida e Kate Chopin, Júlia Lopes publica seu primeiro romance, A família Medeiros, como folhetim na Gazeta de Notícias do Rio de Janeiro. Publicado como livro em 1894, Horacio Belfort Sabino, seu editor, salienta "o fato raríssimo de se haver esgotado a primeira edição em cerca de três meses" (Almeida, 1894, p. 4 apud MOREIRA, 2003, p. 76). Apesar de se dizer avessa à política, participou do Congresso Feminista, foi membro da Federação pelo Progresso Feminino, presidida por Bertha Lutz, tendo ainda apoiado a Conferência Brasileira pelo Progresso Feminino. (MOREIRA, 2003, p. 84)
} 


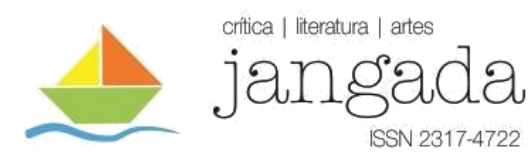

e outras levadas por sua modéstia não têm querido externar seus pensamentos pela imprensa. (...) (O Sexo Feminino, 1874, p. 1 apud DUARTE, 2016, p. 190)

Em 1889, o periódico volta a ser reimpresso, agora com a colaboração das filhas de Francisca, apregoando que a "racional emancipação da mulher não podia nem pode deixar de entrar na arena do combate travado para a restauração dos direitos da mulher..." ( $O$ Sexo Feminino, 1889, p. 1 apud DUARTE, 2016, p. 191). Também Josephina Álvares de Azevedo, fundadora de A Família, desempenhou importante papel na divulgação de ideias em prol da educação das mulheres. De acordo com Constância Lima Duarte, trata-se de um dos periódicos mais importantes do século XIX, dentre aqueles dirigidos por mulheres, no Brasil (DUARTE, 2016, p. 313). O jornal circulou de 1888 a 1889, primeiramente em São Paulo, depois no Rio de Janeiro, tendo circulado nesta última cidade até 1897. Muitas vezes, sob a fachada de iniciar as mães de família e esposas devotadas em seus deveres, tal como se lia no jornal A Família de 18 de maio de 1889, visava a promover a emancipação feminina. No segundo ano de sua existência, em seu aniversário, lia-se que ele havia sido criado com esse propósito. O discurso torna-se mais direto e exaltado, como se vê na crônica "O voto feminino":

No fundo escuro e triste do quadro de provações a que votaram a mulher na sociedade, brilhará, com a fulgente aurora da República Brasileira, a luz deslumbradora da nossa emancipação? (...) É necessário que a mulher, também como ser pensante, como parte importantíssima da grande alma nacional, como uma individualidade emancipada, seja admitida ao pleito em que vão ser postos em jogo os destinos da pátria. (AZEVEDO, 1889)

O questionamento gira em torno da chegada da República: a mudança seria apenas na forma política, ou haveria alterações mais profundas na estrutura social? A mulher, indaga Josephina Álvares de Azevedo, seria integrada como ser participante da vida social, exercitando o pleno direito ao voto? Somente em 1932 tal direito seria conquistado, mesmo assim com restrições: apenas as mulheres casadas, com autorização do marido, viúvas e solteiras com renda própria poderiam votar. Essas limitações só seriam revistas no Código Eleitoral de 1934, e só em 1946 o voto feminino passaria a ser obrigatório. Como se vê, a República trouxe muitas decepções às mulheres, que ainda tiveram (e têm) que persistir lutando por seus direitos.

No século XIX destaca-se, ainda, Nísia Floresta Brasileira Augusta (1810-1885), pioneira não só nas letras como na defesa pelo feminismo. Sua colaboração nos jornais começa 


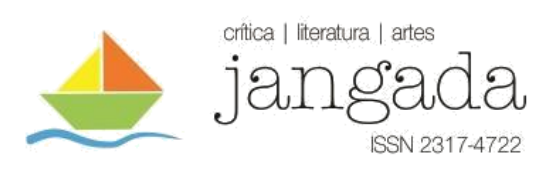

em 1830 no Espelho das Brasileiras, onde escreve artigos sobre a condição feminina. Entre 1853 e 1854, publica "Opúsculo humanitário", um de seus textos fundamentais sobre a educação das mulheres, em dois jornais: no Diário do Rio de Janeiro e em O Liberal. Ao longo da obra de Nísia, nota-se um projeto político bem delineado em prol da defesa dos direitos femininos. Para ela, o progresso de uma nação dependia da posição que a mulher ocupava na sociedade. Mantenedora de um colégio para moças no Rio de Janeiro, também escrevia textos em defesa dos índios e dos escravos, preocupada que era com as questões de seu tempo e com o processo de modernização do país.

Em “Passeio ao Aqueduto da Carioca”, publicado em 1855 n’O Brasil Ilustrado, a cronista empreende um passeio erudito, que forma a opinião de quem lê. Nísia empreende um jogo, uma estratégia por meio da qual faz um mapeamento da cidade do Rio de Janeiro e tece críticas enviesadas, que se dirigem a um - viajante estrangeiro - mas destinam-se a outro brasileiro, carioca, leitor daquele jornal. As críticas se fazem, por meio da ironia, aos homens colonizadores e aos contemporâneos, aos "sábios", às mulheres e à cidade. Vejamos um fragmento:

Não te demores também em nossas ruas procurando os nossos monumentos. Ainda os não possuímos; fomos colônia portuguesa. E depois que nos constituímos nação independente, a grande população da rica capital deste vasto império, por demais dilettanti e de bom tom, prefere despender grossas somas para ouvir lindas cantoras, multiplicar os bailes e outras distrações públicas, a concorrer para expurgar as nossas ruas dos tigres que as infestam! (FLORESTA, 2009, p. 33, grifos no original)

O fato de termos sido colônia de exploração portuguesa fica bem delineado no excerto. Além disso, a escritora critica a população de "bom tom" que, ao invés de se preocupar com o problema da escravidão, com o problema da falta de saneamento básico - expressos na figura do "tigre", escravos encarregados de levar tinas com fezes na cabeça -, apegava-se a futilidades como bailes e festas nos grandes salões. Adiante, problematiza a situação das mulheres:

Uma parte das nossas mulheres continua estacionada na vida caseira, exposta às enfermidades que ela acarreta, e passa a vida em indolente indiferença, ou entregue ao trabalho, que a falta de método torna árduo e muitas vezes sem proveito real; a outra prefere ostentar os seus encantos, ou a elegância do seu 
trajar, nos empoeirados bairros prediletos da multidão... (FLORESTA, 2009, p. 43-33)

Como se nota, a ênfase é o confinamento da mulher ao espaço doméstico, à esfera privada, ao passo que o espaço público era majoritariamente destinado ao homem - fato este que é um dado universal quando se pensa na condição feminina. Isso fica notório em Um teto todo seu, publicado em 1929 por Virginia Woolf, em que a autora narra a impossibilidade de as mulheres frequentarem bibliotecas em universidades na Inglaterra, a menos que estivessem acompanhadas por alguém do sexo masculino ou tivessem uma autorização. Como se vê, o espaço do conhecimento é interditado às mulheres desde sempre e em variadas culturas e países.

Voltando às crônicas femininas, a seriedade no trato aos temas parece ter sido uma constante durante muito tempo. Para finalizar este breve percurso em torno da crônica de autoria feminina, vejamos alguns excertos de Carmem Dolores (1852-1910). Nascida no Rio de Janeiro, teve uma trajetória literária bem diversificada: foi cronista, contista, romancista, dramaturga, tendo se dedicado também à crítica literária e à poesia. Publicou, dentre outros, nos jornais Correio da Manhã, Tribuna, O País, sendo uma das cronistas mais bem pagas deste último. Em alguns periódicos publicou sob pseudônimos. Foi pioneira na luta pela educação feminina, e em seus textos abordava com frequência a condição feminina, em defesa do trabalho da mulher e de uma educação mais qualificada - ainda que não tenha lutado pelo sufrágio feminino. Também o divórcio era algo propagado em seus textos. Nota-se que em Carmem Dolores já se encontra um pensamento crítico acerca da condição das mulheres. Por vezes, a escritora as conclama à luta - a qual se dá, dentre outras formas, pelo acesso à educação -, como aparece na crônica de 6 de agosto de 1905, publicada no periódico O País:

O preparo da sua educação atual [da mulher] bem o indica. Tem de saber lutar, senão, ai! dela, vítima sempre do másculo egoísmo. Precisa de força e de independência própria; precisa de altanaria e de experiência, do contrário tomba na estrada da vida, malferida, pisada, e ainda em cima escarnecida. (VASCONCELLOS, 1998, p. 33)

"Força" e "independência própria" também remetem à proposta de Virginia Woolf: para a escritora inglesa, uma mulher deveria receber 500 libras por ano e ter um teto todo seu para escrever ficção. Ou seja: privacidade e autonomia financeira estarão entre as condições imprescindíveis para que uma mulher se tornasse escritora. Carmem Dolores parece estender tais condições a todas as mulheres. 
Para finalizar, lembremo-nos de que tanto a história quanto a crônica "constroem memória, o que equivale a reconhecer que desenham identidades, sejam elas as identidades de uma geração, sejam elas identidades de gênero, de grupos sociais ou de recortes espaciais bem definidos". (NEVES, 2001, p. 26) Sendo assim, observamos, pelo estudo de algumas escritoras do século XIX, que a crônica assume uma função histórica, ao se tornar um "lugar de memória", mais precisamente de uma memória coletiva, dos começos de uma história feminina pela reivindicação de direitos. É graças a essas precursoras que bem se utilizaram da pena nos periódicos da época que, no século XX, outras conquistas vieram e, mais ainda, outras escritoras tiveram condições de desenvolver seus trabalhos, seja como cronistas, jornalistas ou ficcionistas.

\section{REFERÊNCIAS BIBLIOGRÁFICAS}

ALMANAQUE MULHERES REAIS - MODAS E MODOS NO RIO DE DOM JOÃO VI. Exposição no Palácio das Artes, de 9/10 a 22/11/09, em Belo Horizonte.

ALMEIDA, Júlia Lopes de. Eles e elas. Rio de Janeiro: Francisco Alves, 1922.

AZEVEDO, Josephina Álvares de. O voto feminino. A Família, 1889.

BUITONI, Dulcília H. Shroeder. Crônica/mulher, mulher/crônica. Boletim Bibliográfico Biblioteca Mário de Andrade, v. 46, n. 1/4, p. 81-89, jan./dez. 1985.

CANDIDO, Antonio et al. A vida ao rés-do-chão. In: FUNDAÇÃO CASA DE RUI BARBOSA (Org.). A crônica: o gênero, sua fixação e suas transformações no Brasil. Rio de Janeiro: Fundação Casa de Rui Barbosa, 1992.

DUARTE, Constância Lima. A crônica feminina brasileira: das origens à contemporaneidade. Vivência, Natal, v. 9, n. 2, p. 107-113, jul./dez. 1995.

DUARTE, Constância Lima. Literatura, imprensa e emancipação da mulher no Brasil no século XIX. In: ENCONTRO DA ANPOLL, UFMG, 1 a 3 de julho de 2010.

DUARTE, Constância Lima. Imprensa feminina e feminista no Brasil: século XIX. Dicionário ilustrado. Belo Horizonte: Autêntica Editora, 2016.

FLORESTA, Nísia. Passeio ao Aqueduto da Carioca. In: DUARTE, Constância Lima (Org.). Inéditos e dispersos de Nísia Floresta. Natal: EDUFRN/NCCEN, 2009. p. 33-44. (Coleção Estudos Norte-Rio-Grandenses)

LUSTOSA, Isabel. Prefácio. In: JINZENJI, Mônica Yumi. Cultura impressa e educação da mulher no século XIX. Belo Horizonte: Editora UFMG, 2010.

MACHADO DE ASSIS, Joaquim Maria. O folhetinista. 30 out. 1859. Disponível em: <http://revistaepoca.globo.com/Epoca/0,6993,EPT704502-1655,00.html>. Acesso em: 22 nov. 2019. Publicado originalmente em: In: MACHADO DE ASSIS, Joaquim Maria. Chronicas (1859-1863). Rio de Janeiro: Jackson, 1944.

MEYER, Marlyse. Voláteis e versáteis, de variedades e folhetins se fez a chronica. Boletim Bibliográfico Biblioteca Mário de Andrade, v. 46, n. 1/4, jan./dez. 1985. p. 17-41. 
MOREIRA, Nadilza Martins de Barros. A condição feminina revisitada: Júlia Lopes de Almeida e Kate Chopin. João Pessoa: Editora Universitária/UFPB, 2003.

MUZART, Zahidé L. Uma espiada na imprensa das mulheres no século XIX. Revista Estudos Feministas, Florianópolis, v. 11, n. 1, jan.-jun. 2003.

NEVES, Margarida de Souza. História da crônica. Crônica da história. In: RESENDE, Beatriz (Org.). Cronistas do rio. Rio de Janeiro: José Olympio, 2001.

VASCONCELlOS, Eliane. Carmem Dolores. Crônicas: 1905-1910. Rio de Janeiro: Arquivo Público do Estado do Rio de Janeiro, 1998. (Coleção Fluminense, v. 3)

WOOLF, Virginia. Um teto todo seu. São Paulo: Tordesilhas, 2014. 